\title{
Wind profiling features and atmospheric dynamics: A few first observations from ST Radar of Gauhati University
}

\author{
M. Devi ${ }^{* 1,2}$, S. Patgiri ${ }^{1,2}$, A. Medhi ${ }^{2}$, S. Das ${ }^{2}$, A. K. Barbara ${ }^{1}$, R. Mahato ${ }^{3}$, S. Shaw ${ }^{4}$ \\ ${ }^{1}$ Dept. of Physics, Gauhati University, Guwahati-14, Assam, India \\ ${ }^{2}$ ST Radar Centre, Gauhati University, Guwahati-14, Assam, India \\ ${ }^{3}$ Kokrajhar Science College Kokrajhar, Assam, India \\ ${ }^{4}$ Indian Meteorological Department, Guwahati, India \\ *md555gu@gmail.com
}

\begin{abstract}
The windfeatures in fine spatio-temporal resolutions covering lower troposphere to beyond tropopause, are important inputs for understanding atmospheric dynamics associated with weather and climate. The extraction of information from such features requires complex analysis processes because of involvement of wide dynamical meteorology. Therefore, for study of this type, it is essential to have special atmospheric probing set up along with embedded state of art signal analysis tools, where Stratospheric Tropospheric (ST) Radar proves to be one of the most ideal facility that can provide high resolution wind profiling data covering this defined range. The paper thus attempts to understand the physics and dynamics of the atmosphere associated with complex weather environment of the North East part of India by analyzing wind profiling characters received from the ST Radar, installed at Gauhati University $\left(26^{\circ} \mathrm{N}, 91 .^{\circ} \mathrm{E}\right)$, that offers wind velocity as detailed as $0.1 \mathrm{~m} / \mathrm{s}$ (in vertical mode) with altitude resolution of $150 \mathrm{~m}$. Starting with the calibration of Radar derived wind parameters with Radiosonde and satellite observed data; the analysis here is directed to assess the reliability of wind speed and directions obtained from this setup. The special events like precipitation and thunder time modulations of wind components are also presented and possible system physics for development of such situations has been focused.
\end{abstract}

Keywords: ST Radar; wind profiling-calibration, wind features, worst-weather

\section{Introduction}

It is well known that atmospheric motions reflected in the wind parameters are governed by thermodynamical status dictated by meteorological variabilities like pressure, temperature and density. Thus, 
wind features which are controlled and shaped by dynamical meteorology, could directly provide weather and climate conditions. For such status-information, the parameters that require continuous monitoring are: the process of development of wind, its velocity, mode of propagation, growth of shear and up/down drafts in the wind fields. At present, with the availability of high-end remote sensing devices, the wind development processes are being well studied. But as local environment plays a significant role on weather modification with special references to precipitation and thunder [Johansson and Chen 2003], the complex topography of the North East (NE) part of India, i.e., where the present study is conducted, might play a significant role in modulating the wind field along with the meso-scale circulation system. The paper thus is an exercise to understand such aspects along with the formation mode of convective situation around the boundary layer and the mixing layer dynamics in this NE environment with the high resolution wind profiling data received from the recently installed ST Radar of Gauhati University.

The view of a representative wind circulation pattern (received from satellite) of this NE zone is displayed in Figure 1a, where five arrow heads represent the wind flow directions: from (i) western corridor (arrowhead 1, turns to South West [SW] direction eventually), (ii) eastern corridor (arrowheads 2 and 5), which are North East [NE] components of wind; (iii) NE corridor, the wind vector "2" then turns toward north perhaps controlled by the vast water basin of river Brahmaputra (shown by arrowhead 3 and may enter as South or South East [S, SE] parts of wind component) (iv) and another strong circulation is though Bay of Bengal (BoB), the South East [SE, arrowhead 4] part of the wind vector. More detailed flow patterns of this region only, are shown in Figure 1(b), displaying the complexity of wind modulation character. The Sub-Himalayan belt and aerography also play a significant role in the wind circulation morphology over this zone compared to the rest of the country and here lies the importance of understanding the atmospheric dynamics regulated by such flow and vice versa and the significance of presence of a facuility like ST Radar. 


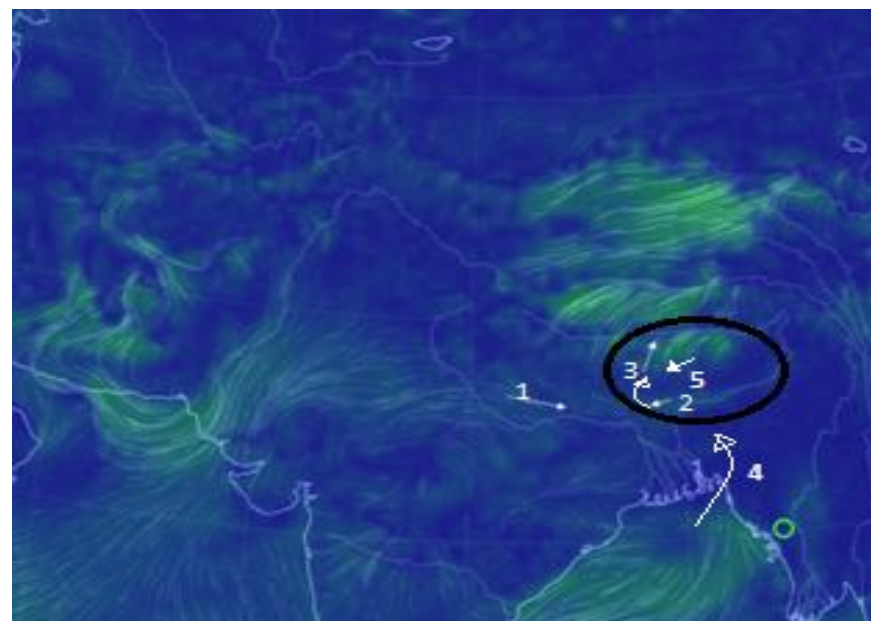

(a)

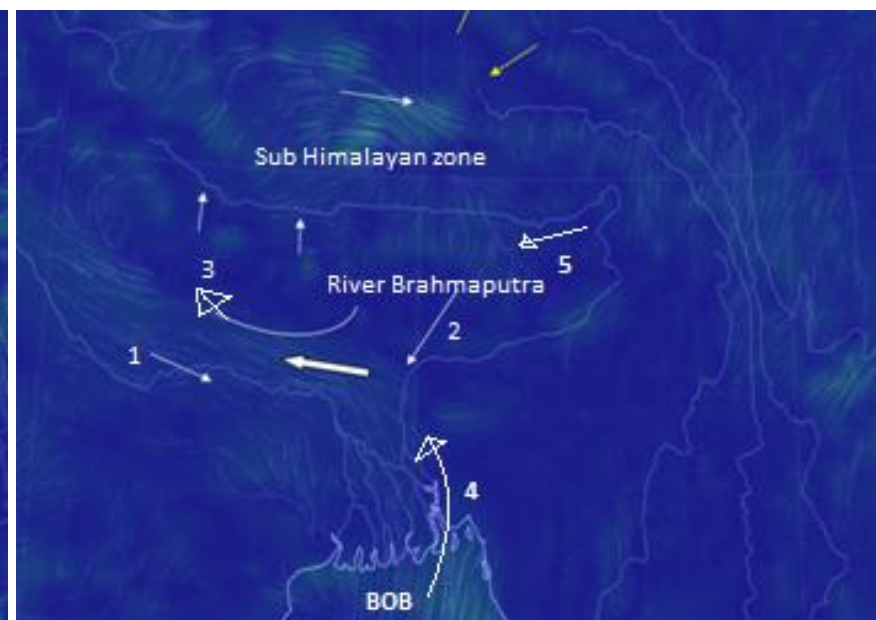

(b)

Figure 1: (a) The wind circulation directions aroundthe NE region of India and (b) the detailed flowpattern focusing NE zone only (a representative display: satellite observations). Arrowheads indicate flow directions.

Most important aspects however are the embedded structures of turbulent vortices and shear within these average wind flow fields, because modulating characters of such structures could dictate the prevailing atmospheric status, with special references to thunderstorm or worst weather situations. Considering these aspects and on high occurrences of thunderstorm activity over this zone [Devi et al., 2014] as well as on the unique rain status compared to the rest of the country (Figure 2), it is considered to be a necessity to create a pool of high spatio-temporal wind data to extract the wind field features and then to understand their contribution in modifying atmospheric system specially during worst weather environments, with the final aim of framing of hazard predictive models.

With this background, a project on Stratospheric-Tropospheric (ST) Radar was framed by the Electronics \& Atmospheric research group of Gauhati University in collaboration with SAMEER, Mumbai. The process of the building up of this facility then started at Gauhati University in 2004 and it took more than a decade to receive the wind data of expected reliability. The Radar is designed at 212 $\mathrm{MHz}$ with $\pm 5 \mathrm{MHz}$ bandwidth in distributed active aperture phased array mode, to probe atmosphere from $300 \mathrm{~m}$ to beyond tropopause. In brief, the Radar is composed of the following subsystems:

(i) Antenna array, (ii) Transmitter- Receiver (TR) Modules (TRM), (iii) Digital receiver, (iv) Signal Processing and (v) Timing and Control signals. The details of the function of the Radar are not discussed 
here, as are available elsewhere [Devi et al., 2020]. The bird eye view of the setup is shown in Figure 3, along with antenna array.

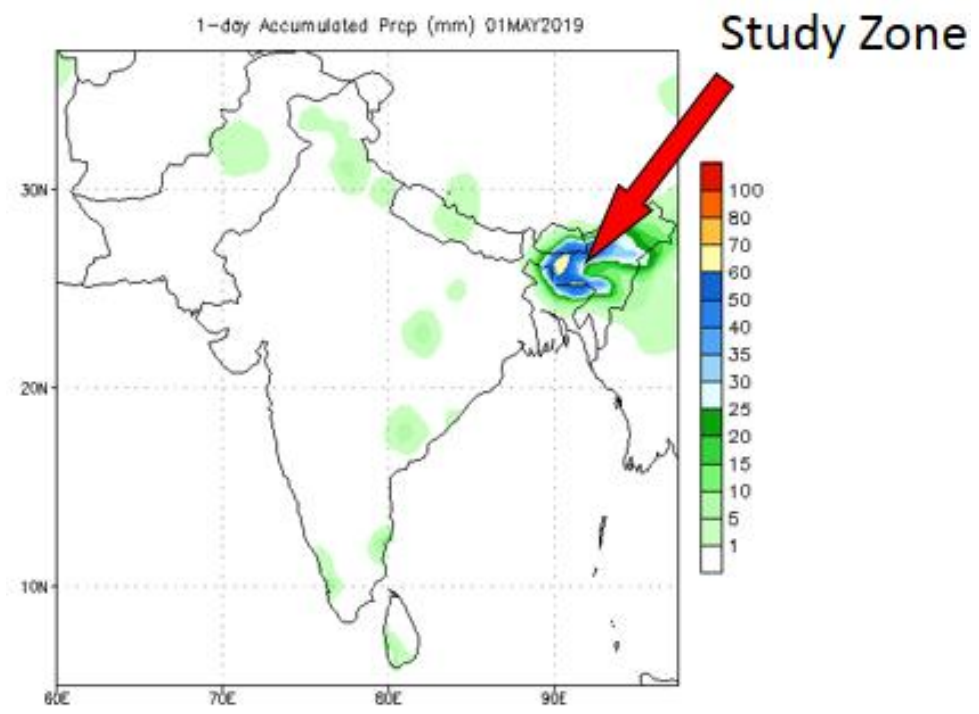

Figure 2: Precipitations when strong in NE region of India (as marked by arrow head), the rest of the country is practically dry: the unique precipitation status of this zone.The color bar provides rain magnitude $(\mathrm{mm})$.

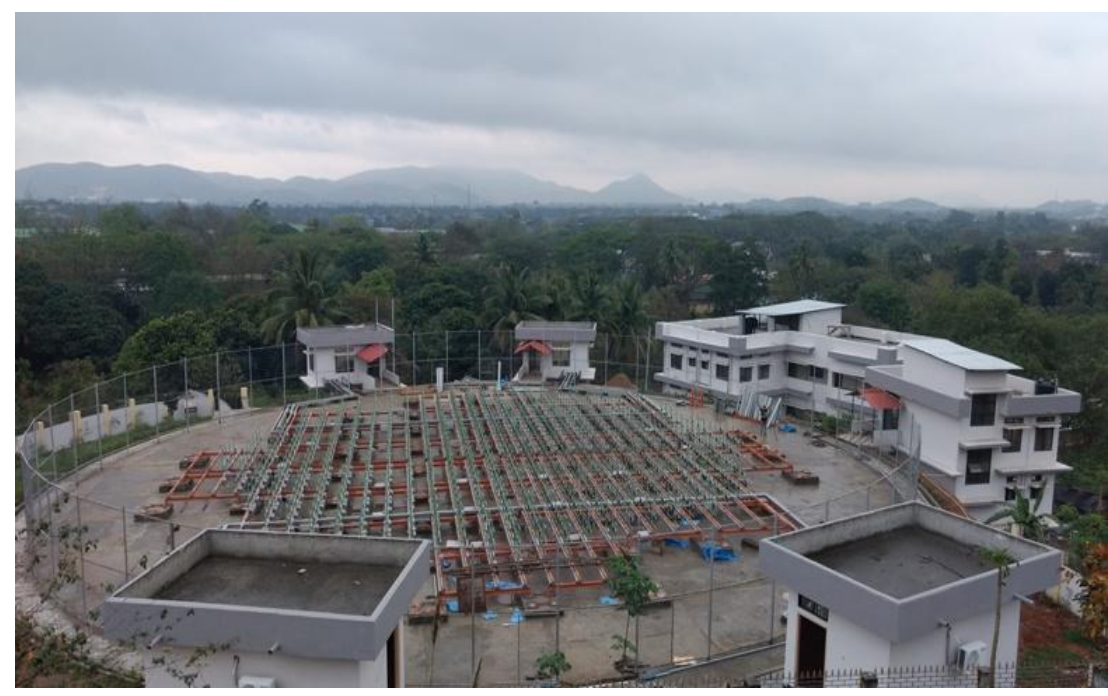

Figure 3: A bird eye view of the ST Radar system of Gauhati University along with antenna array. 


\section{Analysis}

To derive the wind profiling, we start the analysis with the time series data received from Radar Bragg scattered signals. These signals are converted to spectral modes and finally to moments from where $\mathrm{u}, \mathrm{v}$, $\mathrm{w}$ wind vectors are extracted. From these vectors, the wind speeds and directions in zonal, meridional, zenith components and finally the composite wind share derived. If the dwell time for one beam is kept at one minute (approximately), then one frame will be completed in five minutes and there will be 12 frames in one hour. The final wind products are provided in user friendly format. The probing ranges of the Radar are from $300 \mathrm{~m}$ to $5 \mathrm{~km}$ (mode 1, lower mode) and $3 \mathrm{~km}$ to $25 \mathrm{~km}$ (mode 2. higher mode) i.e., covering altitudes from troposphere to lower stratosphere.

The final wind products are provided in user friendly format. The probing ranges of the Radar are from $300 \mathrm{~m}$ to $5 \mathrm{~km}$ (in lower mode) and $3 \mathrm{~km}$ to $25 \mathrm{~km}$ (in higher mode) i.e., covering altitudes from troposphere to lower stratosphere.

The time signal data in moment ' 0 ' give power, moment ' 1 ' provides the Doppler magnitude $(\mathrm{Hz})$, moment '2' while offers spectral width (Hz), moment ' 3 ' gives the Signal to Noise Ratio (SNR). An example of each type of the derived moment is presented in Figures 4. The final output is in NetCDF format, which records the date, month, year and the probing time in IST (Indian Standard Time). The pulse widths for mode 1 and mode 2 are variable from $0.5 \mu$ s to $6 \mu$ s and may be switched to $12 \mu$ s and $16 \mu$ s depending on the requirement and code length.
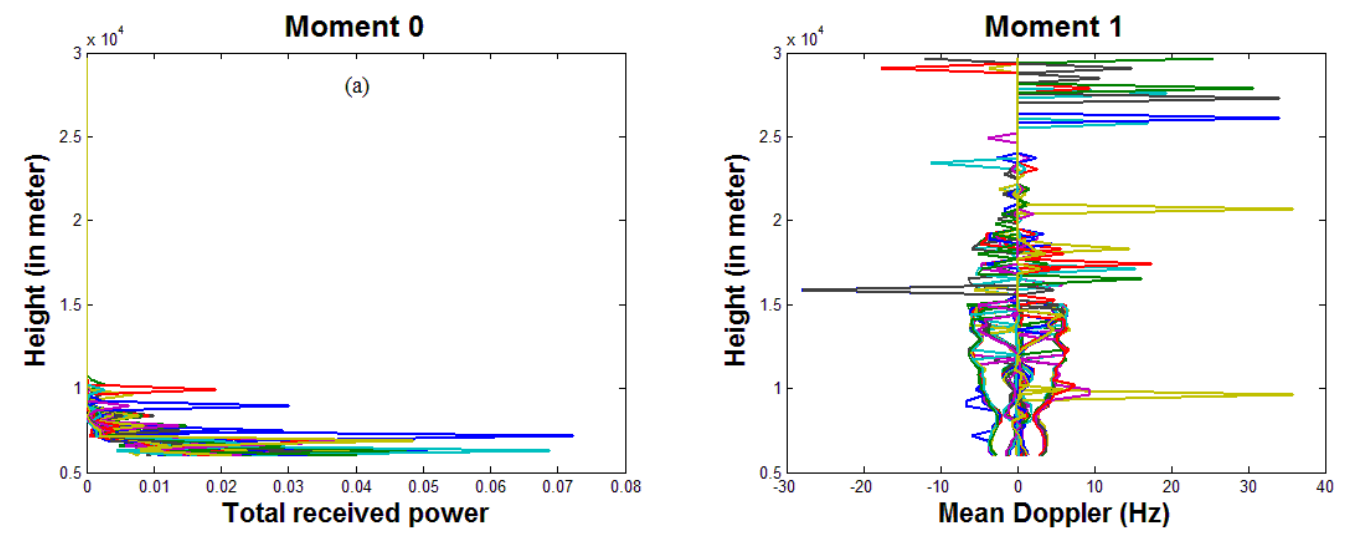

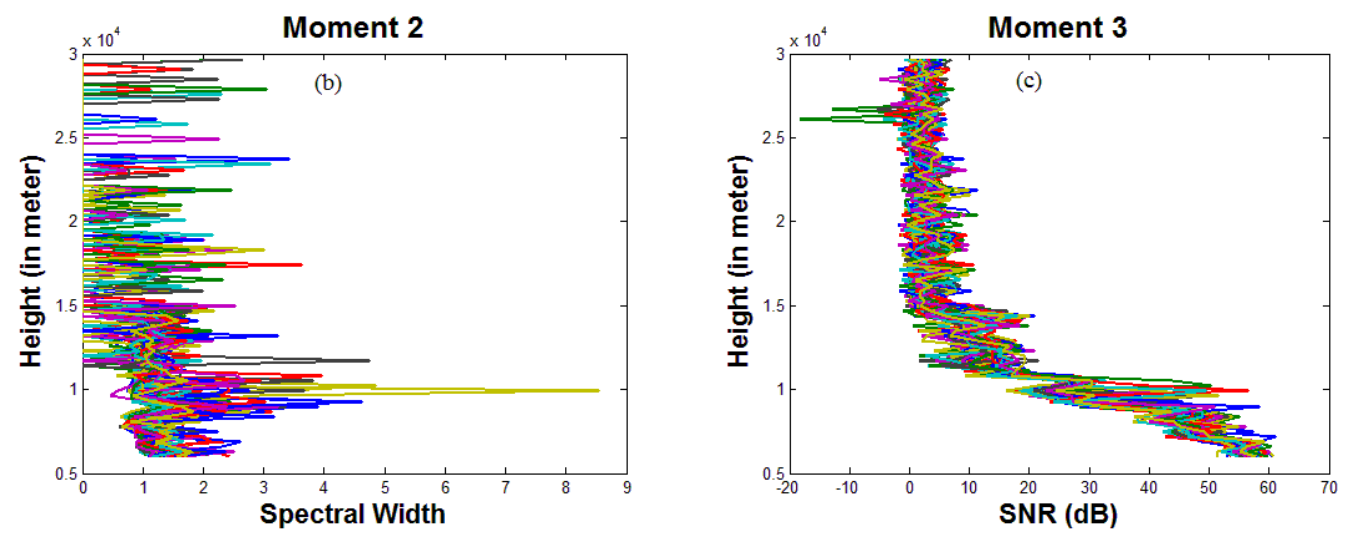

Figure 4: Displaying sample outputs from radar in terms of four moments

The Doppler shift echogram so obtained from moment is shown in Figure 5, as a representative plot for East wind vector. The clear Dopplercomponent seen in the figure from altitude $3 \mathrm{~km}$ to $22 \mathrm{~km}$ indicates presence of relatively strong westerly component of wind beyond tropopause, at the time of probing.

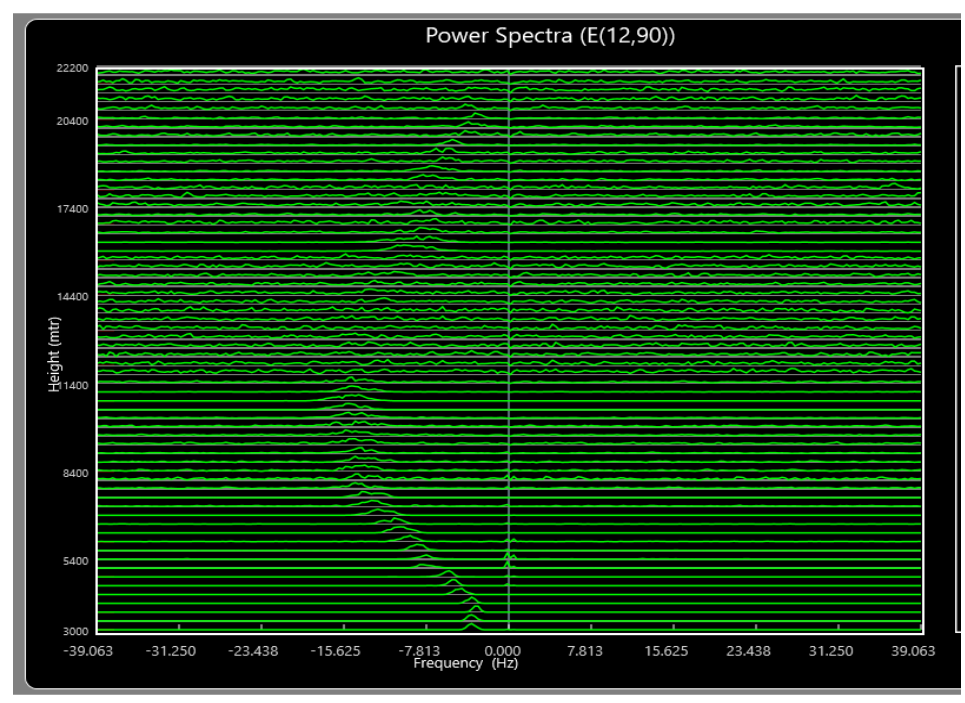

Figure 5: Doppler shift beyond tropopause as obtained from the ST Radar, E beam: a representative display.

Once the ST Radar starts providing the wind profiling, the next essential action, is to validate the wind data with known sources before analyzing the relevant parameters for extraction of atmospheric information embedded in the wind field. So, starting with thecalibration process, we will finally present the analysis output as per the defined aims of the paper 


\subsection{Calibration of ST radar wind profiling with Radiosonde observation:}

To assess the reliability of the Radar derived wind parameters, theprofiles are compared with those received from India Meteorological Department (IMD) Guwahati, a station situated at $8 \mathrm{~km}$ in the Line Of Sightdistance from the Radar facility at GU. A number of such wind profiles are examined primarilywith compositewind components, which are available from IMD balloon observations, twice a day.The profiles are selected fordifferent months, as season to season variations in wind speed as well as directions are important inputs for understanding wind circulation sources. As representative cases, a few such wind speed profiles for the late winter,vernal equinox and early summer season are shown in Figure 6 and Figure 7.

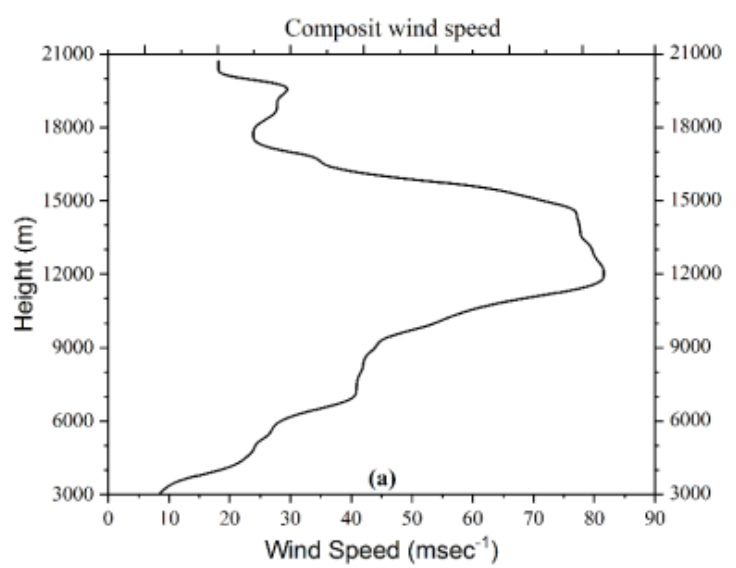

(a)

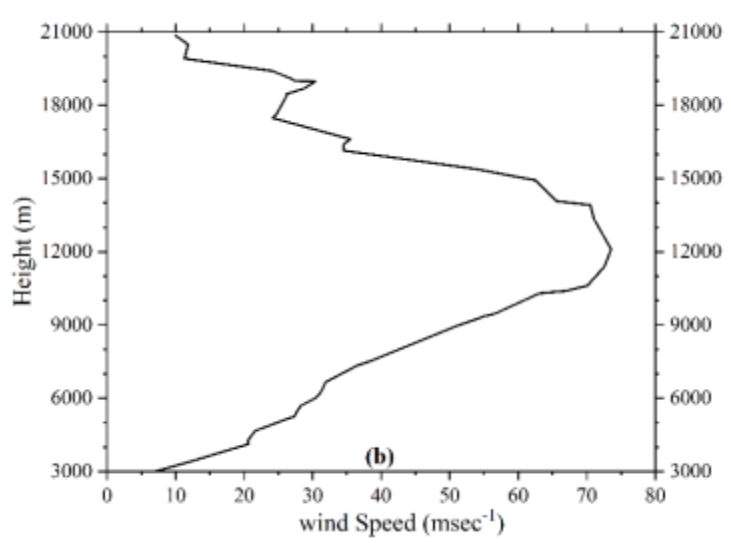

(b)

Figure 6: (a) Wind profile on February (late winter) 2019 from ST Radar of GU and (b) from IMD Guwahati for the same day.

Figure 6a displays the ST Radar derived wind speed profile for a late winter month and Figure $6 \mathrm{~b}$ shows that received from the IMD for the same period. The synchronizations between the profiles in terms of wind speed, peak magnitude and profile-shape, show thequality-data provided bythe ST Radar. The reliability of Radar data is also displayed in Figure7, where the two sets of wind speed echograms (from ST Radar and IMD) are superimposed demonstrating their overall coherency in the season to season changes in wind speed. Thus, the Radar data are expected to provide reliable dynamical status of the atmosphere with finerdetails supportive to theunderstanding on the complex growth processes of a hazard environment. 

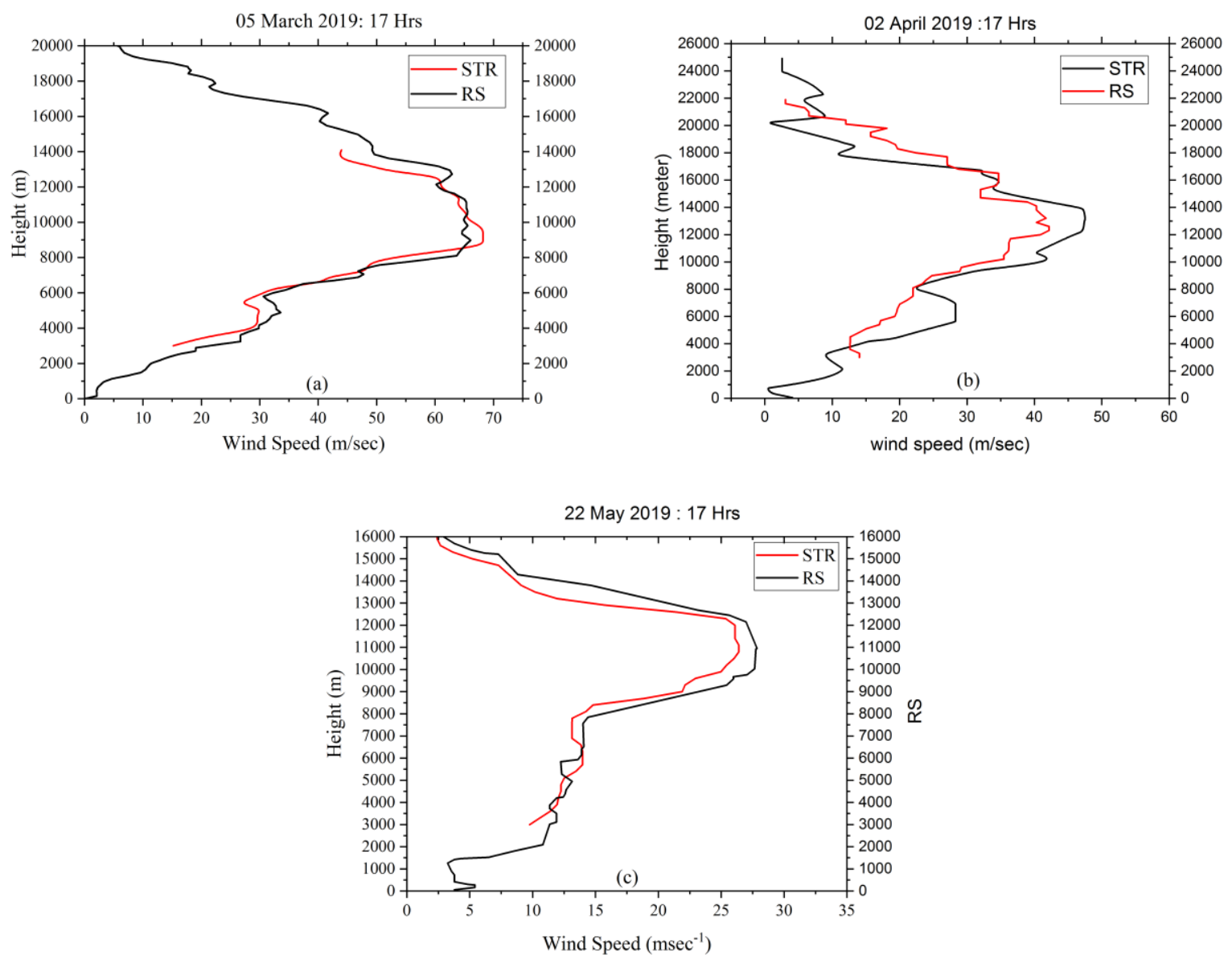

Figure 7: A few wind-speed profiles from ST Radar (marked in red) and Radiosonde (marked in black) in the process of Calibration. The synchronization between the two sets of profiles is apparent both in speed and profileshape. Note the seasonal changes in wind speed

Before one goes for identifying "Hazard-time wind features", it is essential first to examine the overall seasonal variations in wind speed and directions; therefore, the relevant exercises on extraction of seasonal wind features from the Radar are presented as a priority which will then be followed by special event analysis.

\subsection{Seasonal variations of wind speed :ST Radar \& Radiosonde observation}

The information carried by the Figures 6 and Figure 7, implies that, there is a strong seasonal bias component in dictating the peak wind speed. So as a follow up to the above exercise, we will present here the seasonal modification in peak wind speed derived from the Radar at around tropopause height, which will finally be compared with those observed from Radiosonde. 
Going back to the Figure 6, and Figure 7, the wind speeds of $60 \mathrm{~m} / \mathrm{s}-70 \mathrm{~m} / \mathrm{s}$ attained at the altitude of 12/13 km (just below tropopause) during late winter months(Figure $6 \mathrm{a}, \mathrm{b}$ ) and early equinoxial season (Figure 7a) are the seasonal maximum and with the approach of mid-vernal equinoxial season (April) and then to early summer (May) month, the peak wind speed decreases respectively from $40 \mathrm{~m} / \mathrm{s}-50 \mathrm{~m} / \mathrm{s}$ to $25 \mathrm{~m} / \mathrm{s}$ as displayed by the Radar profiles ( Figure 7 b,c). The peak wind speed may further go down from $18 \mathrm{~m} / \mathrm{s}$ to $20 \mathrm{~m} / \mathrm{s}$ in mid summer (Figure $8 \mathrm{a}$ ) to as low as $5 / 6 \mathrm{~m} / \mathrm{s}$ during late summer month (Figure $8 b)$. Such decrease in wind speed near to the tropopause is also noted as the season moves towards autumnal month (not shown).

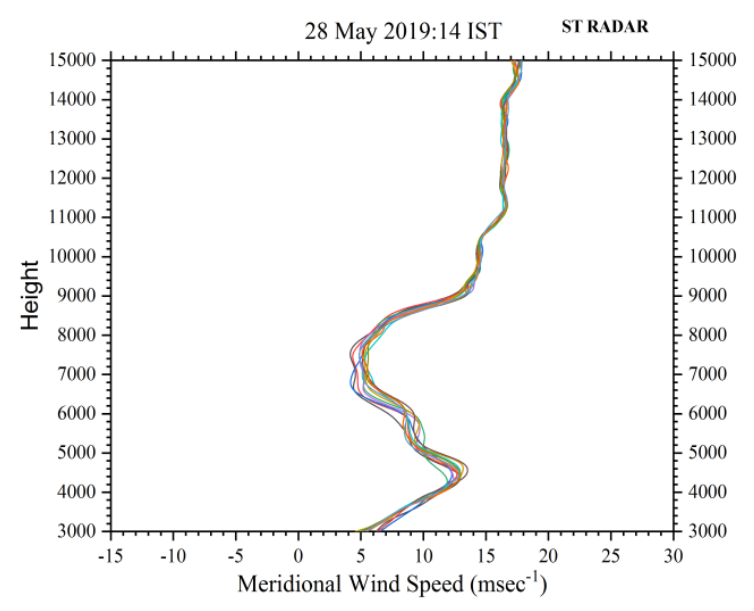

(a)

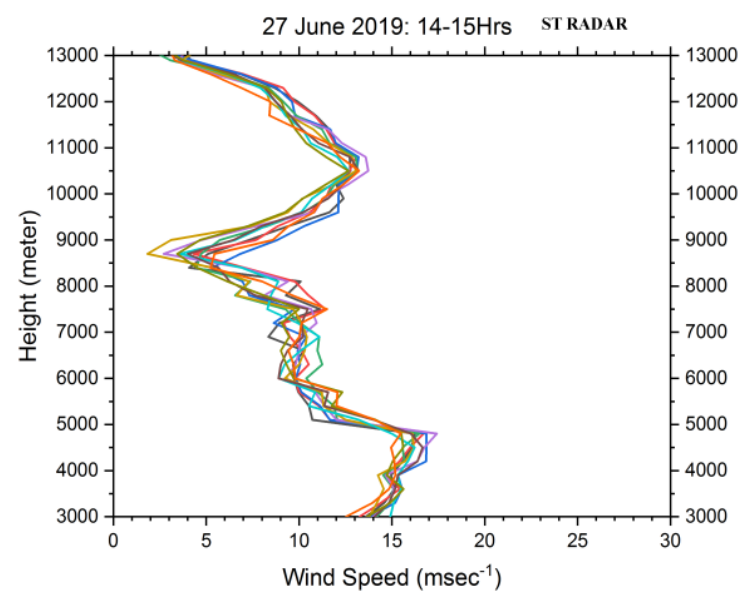

(b)

Figure 8: Wind speed during (a) mid-summer and (b) late summer months. Note significant decrease in its value from that of late winter month of February (Figure 6a).

\subsubsection{Wind speed at lower height}

The wind speeds at lower heights (300 $\mathrm{m}$ to $6 \mathrm{~km}$ range) also show decrease in their valuesas season moves from early summer to Autumnal equinoxes. Figure 9(a) displays that the maximum wind speed of $25 \mathrm{~m} / \mathrm{s}$ (at around $6 \mathrm{~km}$ ) during early summer season reduces by three-fold during late September (Figure 9b). However, these wind flow patternsbeing controlled by the monsoon activities (Summer to early Autumnal season), a long period of study is essential for understanding contribution of monsoon-time tracks, to the wind circulation over this zone. 


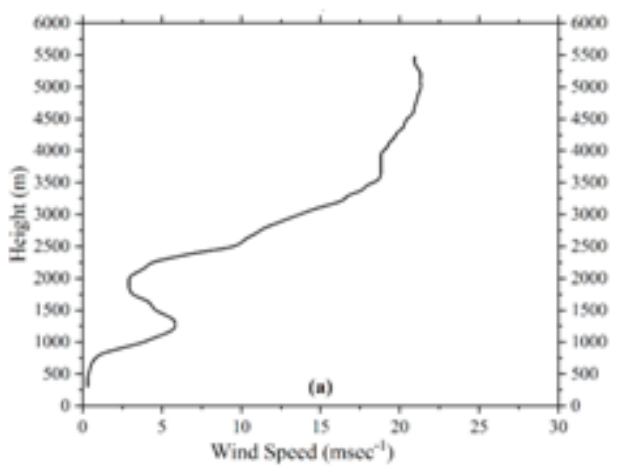

(a)

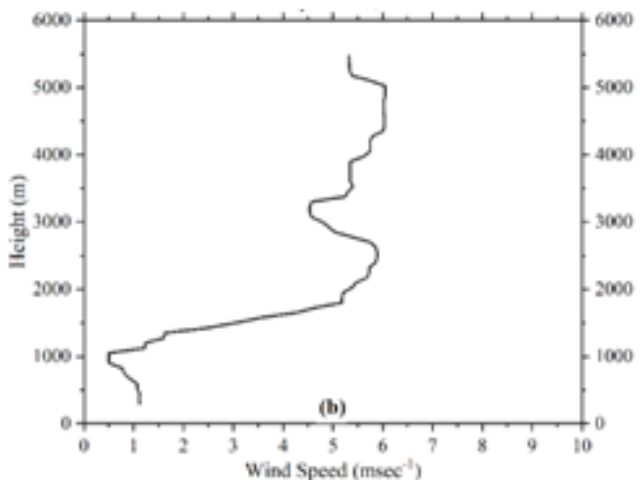

(b)

Figure 9: Composite wind speed variations with altitude (lowerrange: mode 1 operation) at different seasons: Representative profiles of (a) early summer, May, (b) Late Autumnal equinox, September, as received by ST Radar of GU.

Finally in Figure 10, we present a comparative display of seasonal variations on maximum wind speed (near to the tropopause) received from ST Radar (the associated error bar is marked in blue) and those from Radiosonde. The result of the figure is an index that the ST Radar derived wind is well validated and the system performance is adequate for identifying finer details of wind features when situation arises.

The next exersise followed is the calbratiin of Radar derived wind direction.

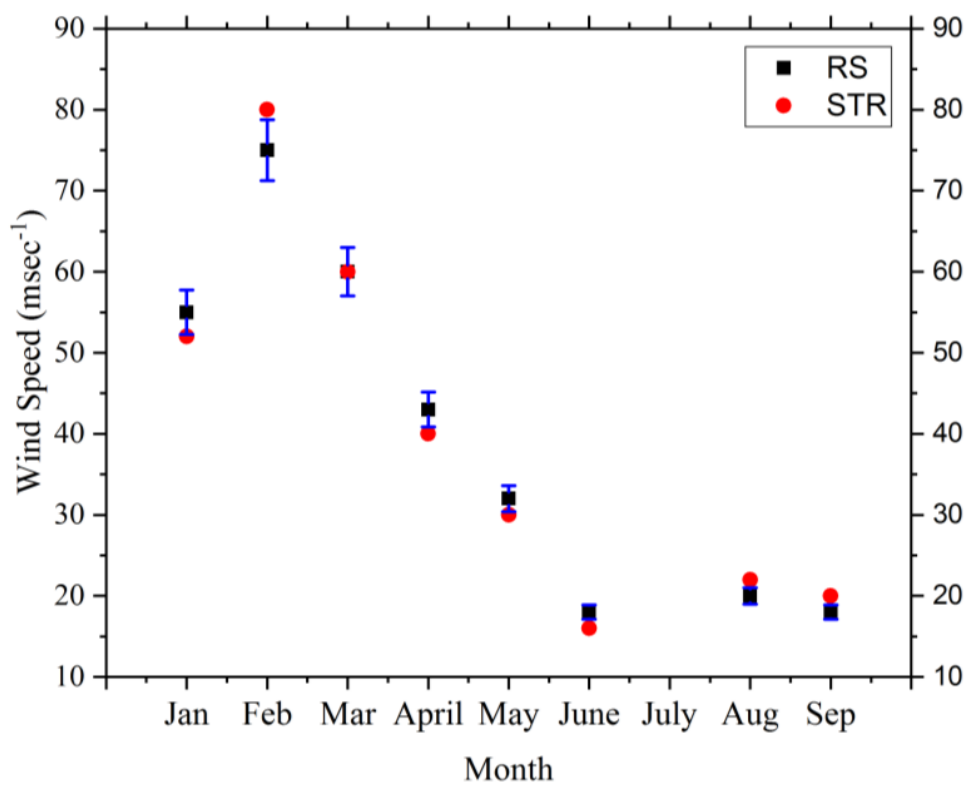

Figure 10: A comparative display of seasonal variations of peak wind speed received from ST Radar (red dot for data point with error bars asblue line) and Radiosonde (black dot). 


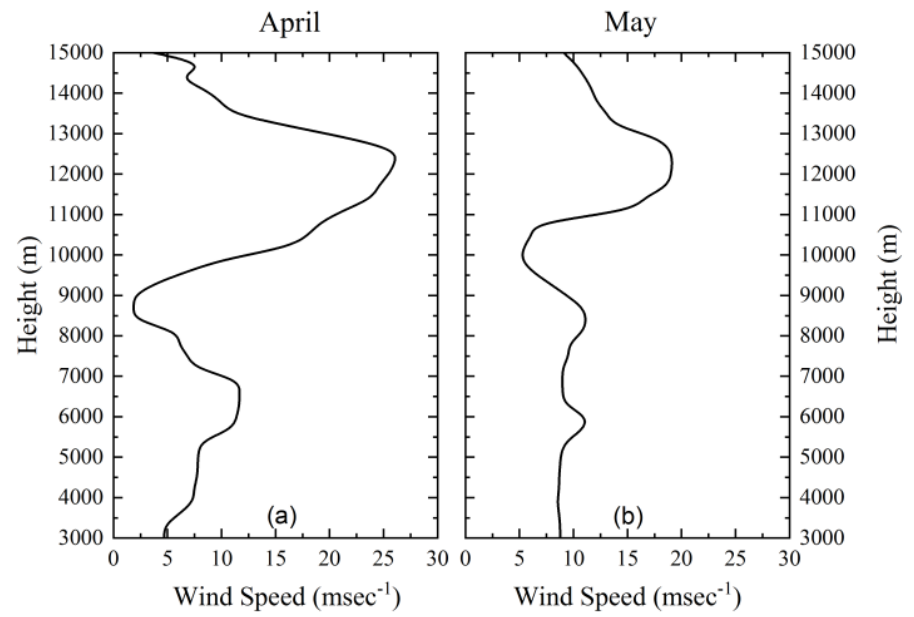

Figure 7: Wind speed in (a) mid vernal equinoxial month and b) early summer. Note decrease in peak speed from that of winter.

As the season moves to the end of summer or early Autumnal equinox, the peak wind speed slows down a little as can be viewed from the radar data as displayed in Figure. 8 ( a) and that obtained by radiosonde observations [Figure 8(b)]. Both the profilers maintain correspondence in wind speed variations with altitude as well as in the peak wind speed values of about $20 \mathrm{~m} / \mathrm{s}$.

The composite wind speeds at lower height ( $300 \mathrm{~m}$ to $6 \mathrm{~km}$ range) also show decrease in value by more than three times in early Autumnal equinoxes compared to summer month of May ( late vernal month as displayed in Figure 9a and Figure 9b respectively .
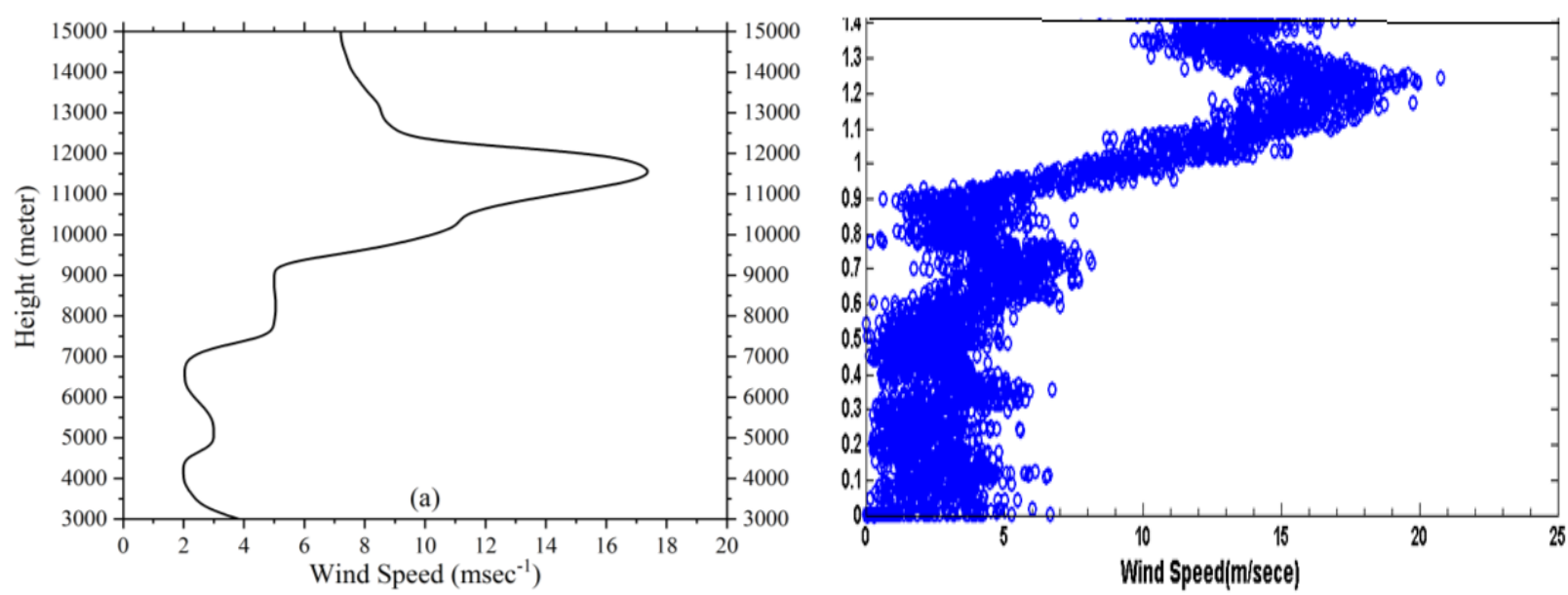

Figure 8: Composite wind speed variations with altitude received on a late summer /early vernal equinoxial month 23.8.2019 from (a) ST radar and (b) from IMD. 

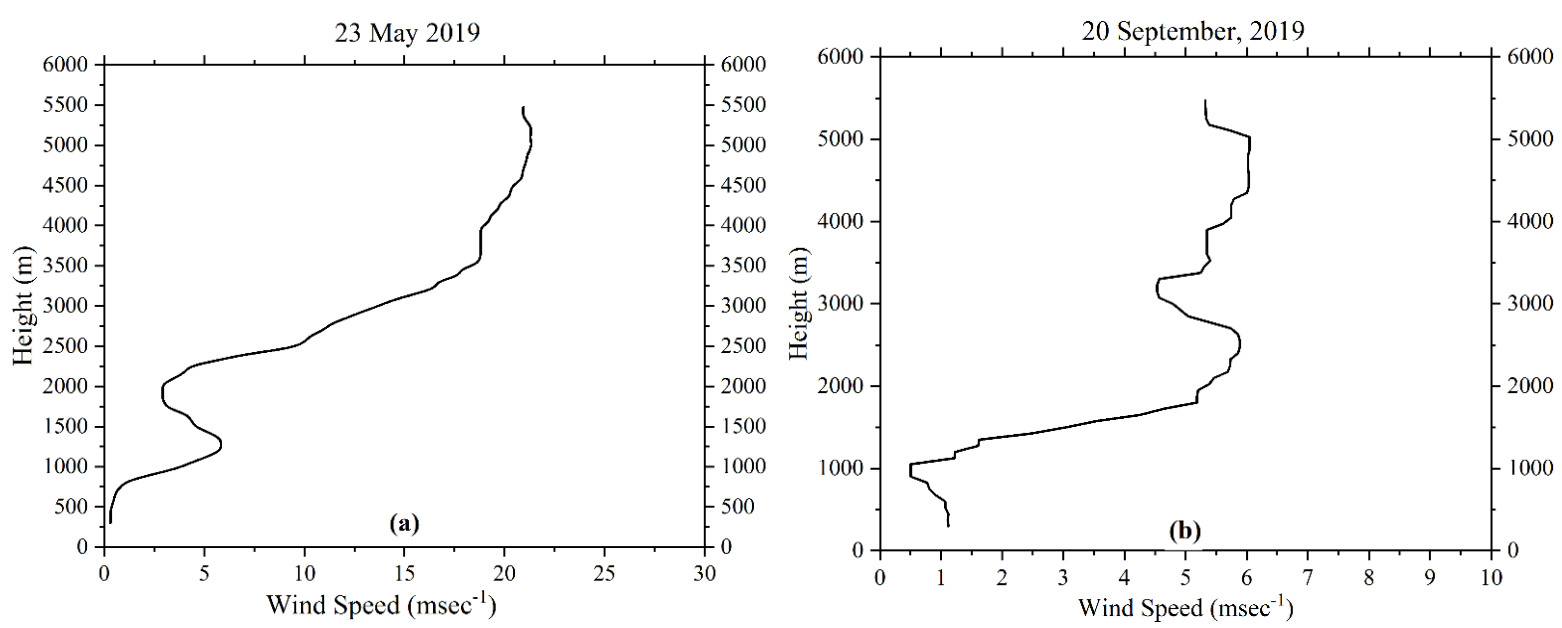

Figure 9: Composite wind variations in (a) early summer month of May 2019 and (b) in Autumnal equinoxial month.

Finally in Figure. 10 a comparative result on seasonal variations on maximum wind speed received from both the facilities are presented. The radar results with one to one correspondances in seasonal varitions in peak wind speed with radiosonde derived values are remarkable and promising.

\subsection{Wind Direction: validation of Radar data}

Wind circulation system involves complex meteorology where aerographic environment plays a major role along with mesoscale flow dynamics. Significantly, wind direction can offer valued information on origin of such wind sources and thus, analysis of its flow pattern at different seasons provides inputs for understanding complex dynamics involved. It is essential therefore to derive the seasonal pattern of wind direction over this zone where fine resolution ST Radar data in two different modes are likely to feed excellent information for such study.

In Figure 11, a few Radar derived wind directions are presented, operated in mode 2 sounding, along with those from IMD balloon data. In vernal season, the wind direction lies within South (S) to SE with slight inclination in SW direction, as displayed by Radar (Figure 11a) as well as by Radiosonde (Figure 11b) observations. The average range of the wind directions are covered by an ellipse in the figures. The extension of analysis period to other seasons shows that with the approach of summer months. The flow of air modulates SW (significant) to W, as displayed both by Radar and Radiosonde. The significant flow 
directions are marked in both the figures (Figure11c and 11d) by an ellipse. In lateAutumnal season (Fighre11e and 11f) the wind circulation has two different significant components depending on altitudes; while a SE direction wind predominates at lower height (marked by ellipse), the NE component is strong at the higher altitude as marked by a rectangle in Figure 11e and Figure 11f, received respectively, from Radar and balloon observations.

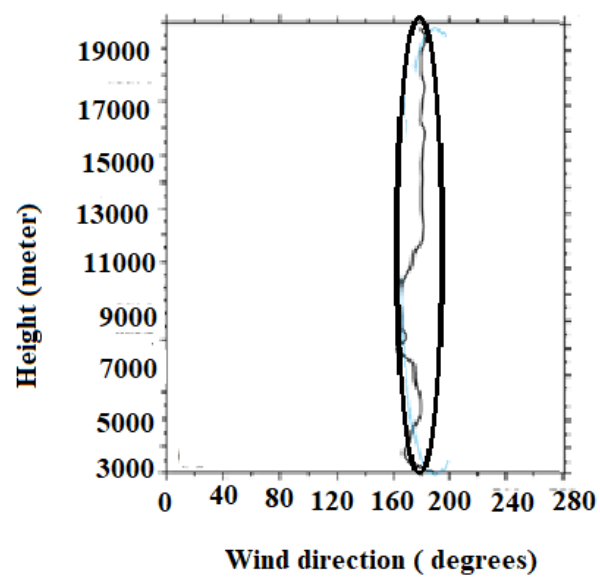

(a)

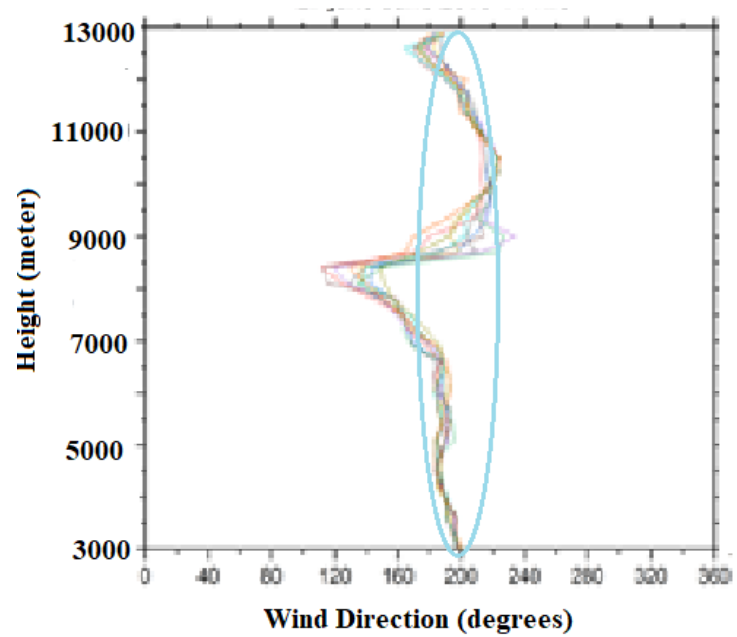

(c)

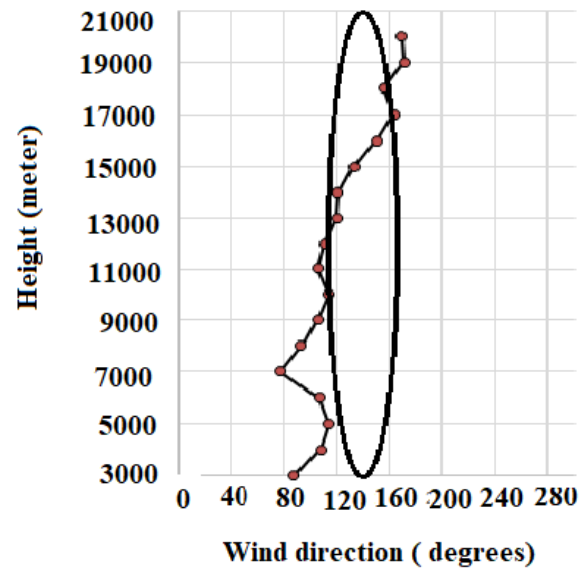

(b)

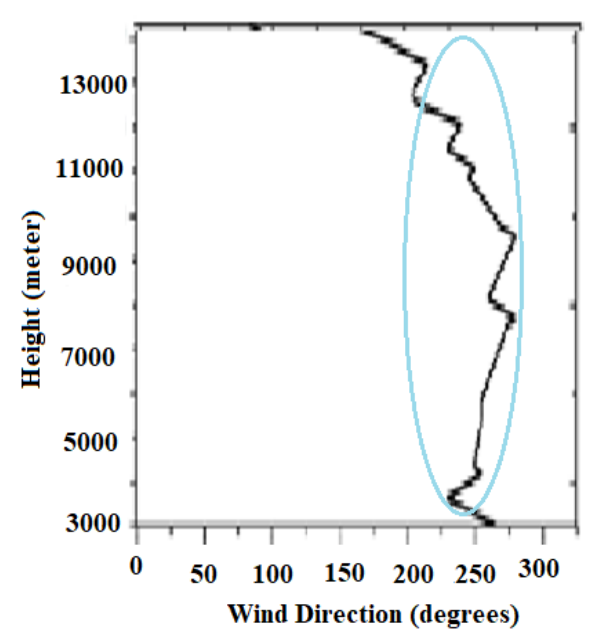

(d) 


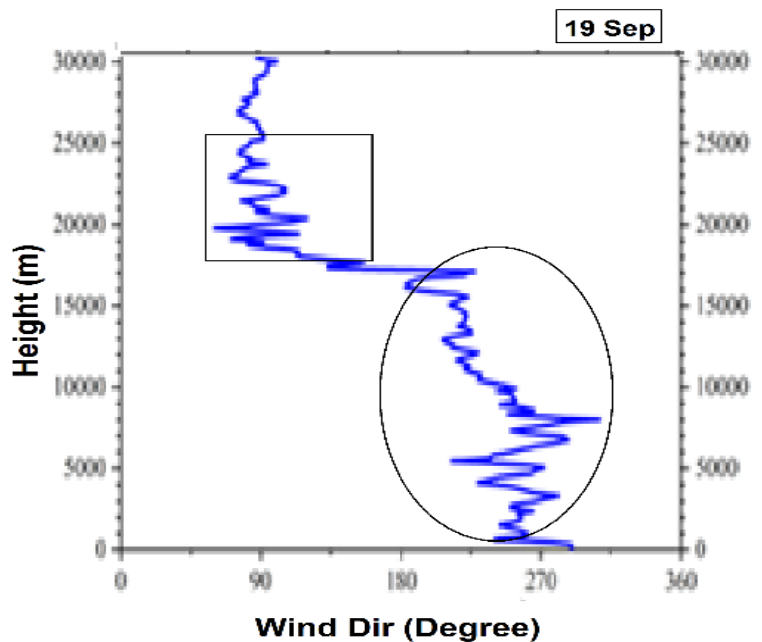

(e)

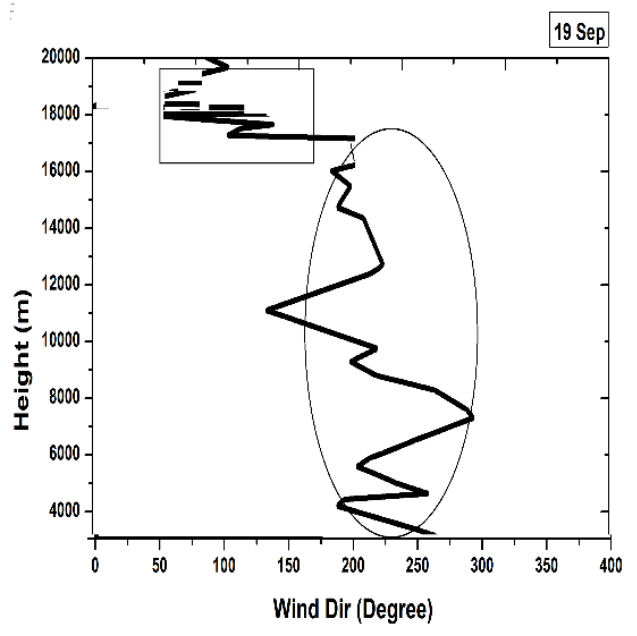

(f)

Figure 11: A few wind direction representative profiles for late Vernal Equinox /early summer: (a) ST radar and (b) Radiosonde; Summer month : (c) ST Radar (d) Radiosonde and during Autumnal equinox month: (e) ST Radar and (f) Radiosonde. Note that average wind flow directions are marked by ellipse in case of Vernal equinoxial and Summer seasons but during Autumnal season there are two distinct wind components at lower and higher altitudes as marked by ellipse and rectangle respectively.

The flow directions from both the setups show over all good synchronization with the season to season changes.

\subsubsection{Wind direction within altitudes from $300 \mathrm{~m}$ to $5 / 6 \mathrm{~km}$}

The wind vectors at the lower reaches of the atmosphere from $300 \mathrm{~m}$ to $6 \mathrm{~km}$ slab, might not present a similar overall flow direction as that of upper atmosphere because of strong control of surrounding terrains on air movement (as in case of our study zone). We thus present here wind directions in mode 1 (lower range) soundings from Radar, keeping each scan frame of 5 minute durations and pulse width of $0.5 \mu$ s so that resolution comes to $150 \mathrm{~m}$ within this altitude range. Radiosonde measured wind direction will be supplemented when needed.

Starting with autumnal season, we present Radar obtained wind direction in Figure 12a, where a predominant westerly component almost all along the altitudes range is noted with a slight inclination to S-W direction. Radiosonde data also revealed a strong S-W component of wind at the lower reaches (Figure 12b) of the atmosphere during this period. However, just at the lowest probing range, the wind 
direction goes to NW in a few frames of Radar observations. The arrowhead in the figures provide average wind directions.

The global satellite wind map also shows (Figure 13) that the net wind component to this zone is South Westerly ( SW, at $850 \mathrm{mb}$ level).

September 2019
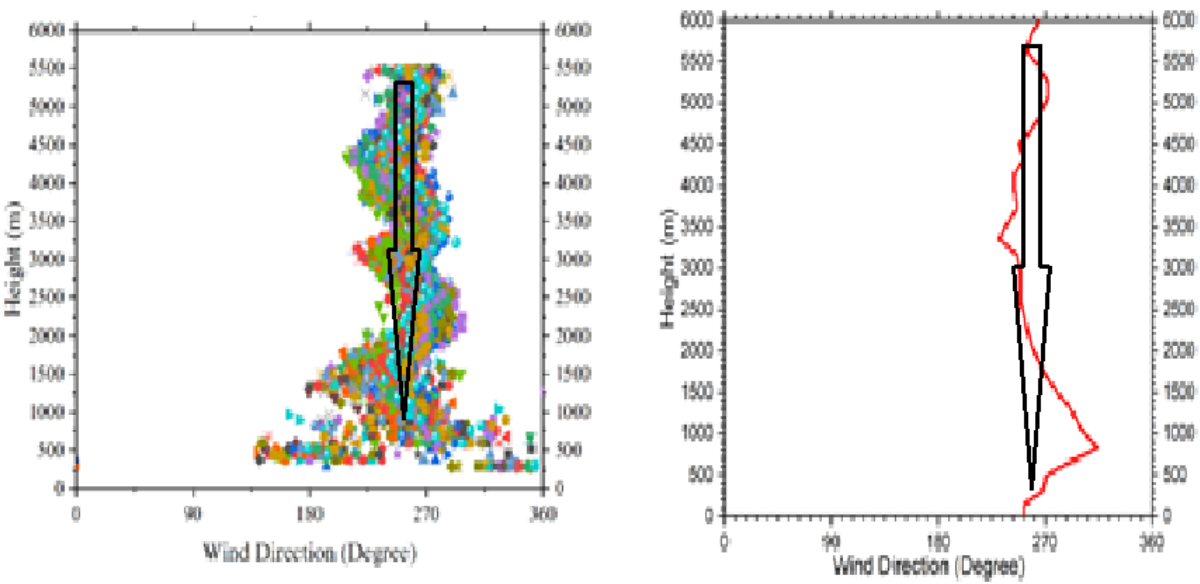

Figure 12: Wind direction in Autumnal equinoxial season at the lower reaches of the atmosphere. Note that both (a) ST Radar and (b) Radiosonde show presence ofWesterly to SW wind component.

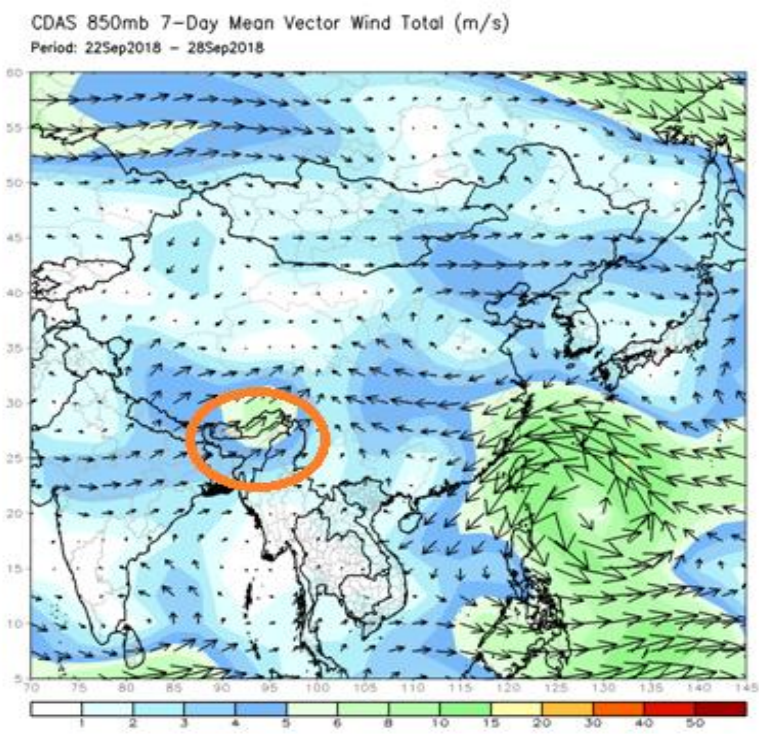

Figure 13: Satellite global wind map displaying presence of SW wind component in the studied zone (circled) during September at $850 \mathrm{mb}$ level. 
During early summer, the southward (S) wind component to the region is more predominant at the lower slab of atmosphere ( Figure 14).

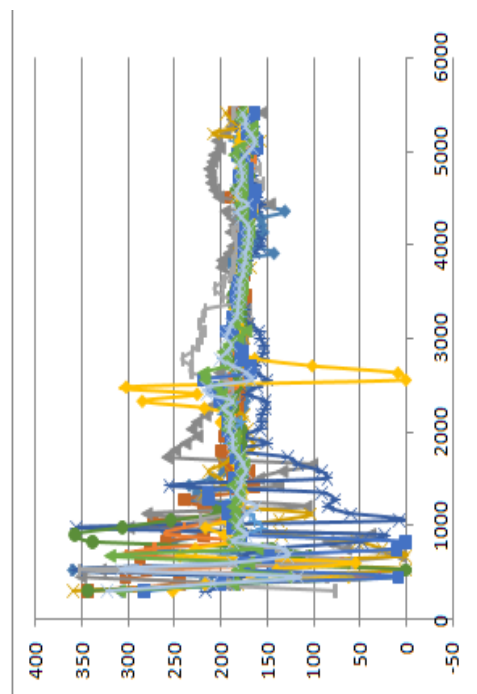

Figure 14 : Wind direction from ST Radar during early summer month. Note the predominant component being South with a slight westerly vector

The satellite global map (Figure 15) also displays presence of the predominant Southerly component of wind at $850 \mathrm{mb}$, during this month.

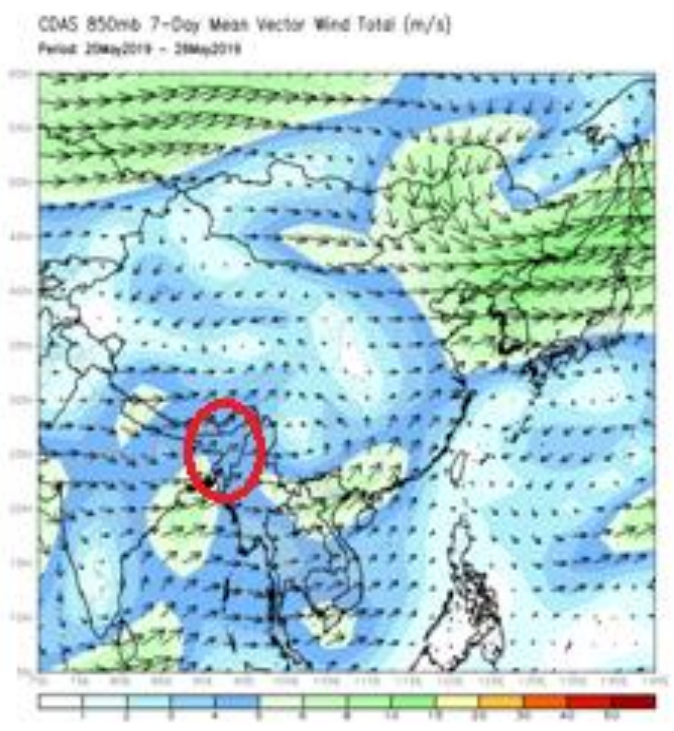

Figure 15: Global wind direction map indicating an overall strong southerly component of wind in this zone (circled) during early summer month. 


\subsubsection{Wind Direction: Over all components}

The above calibration exercises on wind direction also result to the reliability of the Radar data, in support to our observation obtained through wind speed analyses. Finally, all the significant wind flow components of the zone, are presented in Figure 16, displaying an existence of a complex wind circulation system, a broad satellite based view of which was presented in Figure 1. However, for mapping of seasonal wind circulation pattern, such short period of observation may not be sufficient and a significant volume of data from the Radar, spreading over a few years are necessary. This is our future course of study.

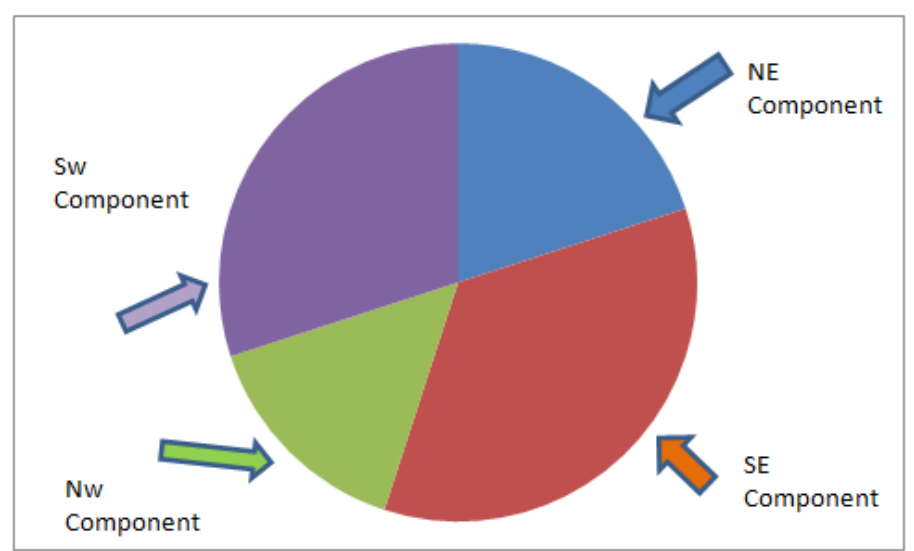

Figure 16: Significant wind circulation components over thestudy zone

We also put emphasis that such fine resolution data from the Radar even limited to a short period, could provide excellent information for understanding atmospheric modulation processes during fast changing wind fields, in situations like worst weather. A few cases will be now presented.

\section{Precipitation time modifications in wind features}

We now arrive to our final target on extraction of features in wind field during precipitation and worst weather situations. The presentation started with display of changes in zonal and meridional wind vectors during moderate to low precipitation event, as heavy rainresults to a complexdynamics to identifying the precipitation-time induced wind features. In Figure 17, the zonal wind components from $300 \mathrm{~m}$ to $6 \mathrm{~km}$ altitudes received from ST Radar during a precipitation environment [(Figure 17a (May 23, early 
summer)] are presented. One can see from the figure that wind vectors get modified from frame to frame and within 5 minutes intervals there are changes in directions from North to South along with variations in speeds from $0 \mathrm{~m} / \mathrm{s}$ to $20 \mathrm{~m} / \mathrm{s}$. But during a non-precipitating situation, the zonal wind variations [Figures $17 \mathrm{~b}$ (May 28, 2019)] offer uniform speed and direction in the all the frames during the entire profile.
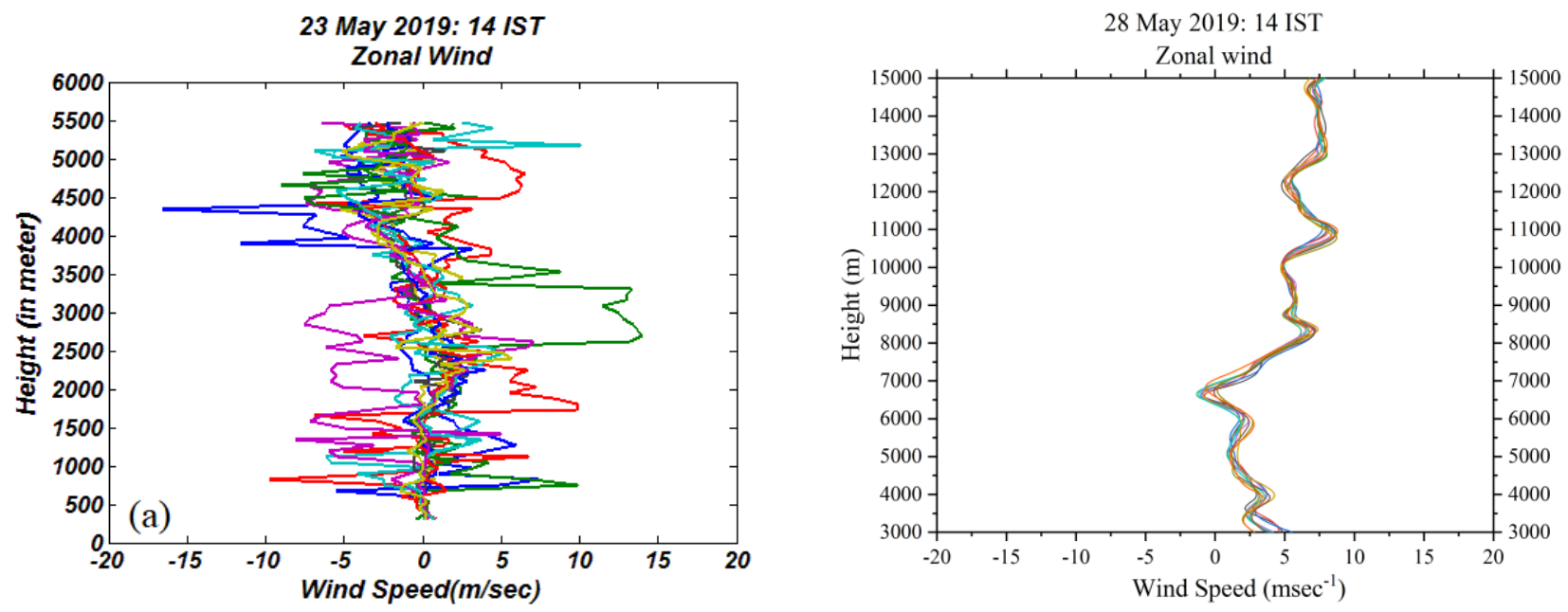

Figure 17: Zonal wind components (a) during precipitation condition and (b) in no rain environment.

The rain-gauge placed at the Radar site recorded day-long rain on May 23 with more than 4mm of rain at $1400 \mathrm{hrs}$., as displayed in Figure $18 \mathrm{~b}$, but on May 28, there was no rain except for $0.5 \mathrm{~mm}$ at $10 \mathrm{hrs}$ $11 \mathrm{hrs}$ (Figure 18a) suggesting modulation inthe wind profiling of May 23 is induced by the precipitation.

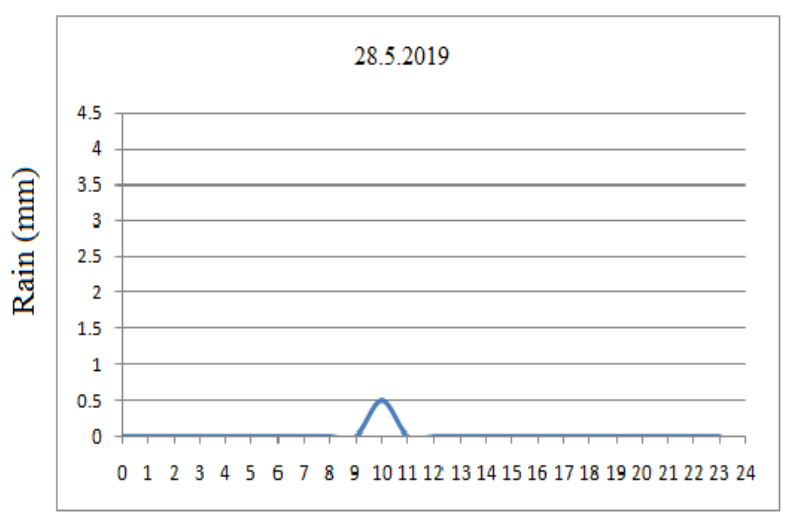

Hours

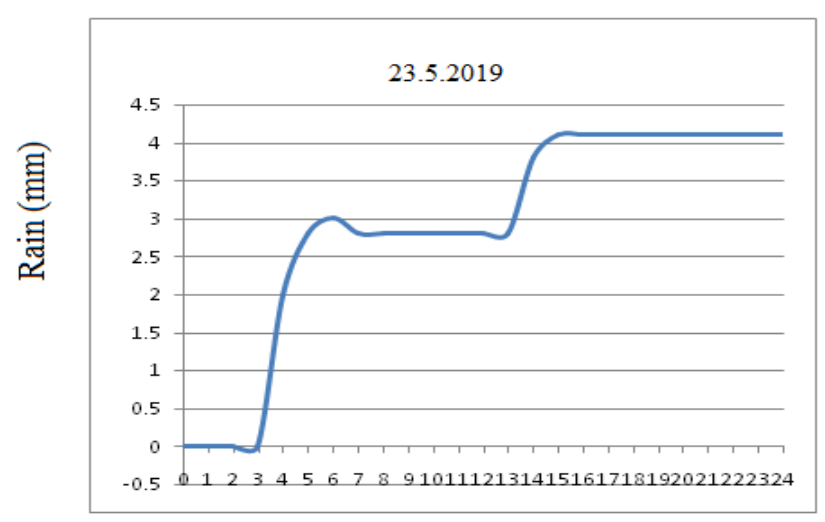

Hours

Figure 18 : Rain records from a digital recorder installed at the ST Radar site: (a) May 28 and (b) May 23. 
In a thunder storm event too, wind vectors undergo similar changes but modulations in the profiles are stronger even if accompanied by mild precipitation. We present in Figure 19, the modification in zonal wind profiles one hour before (Figure 19a) and at the time of the storm (Figure 19b) of March 26, 2019, that occurred at $1300 \mathrm{hrs}$ over Guwahati.The associated other storm time features like development processes of updraft/down draft that have been well detected in the vertical wind vectors of the Radar will not be discussed here and are reported elsewhere [Devi et al., 2020].
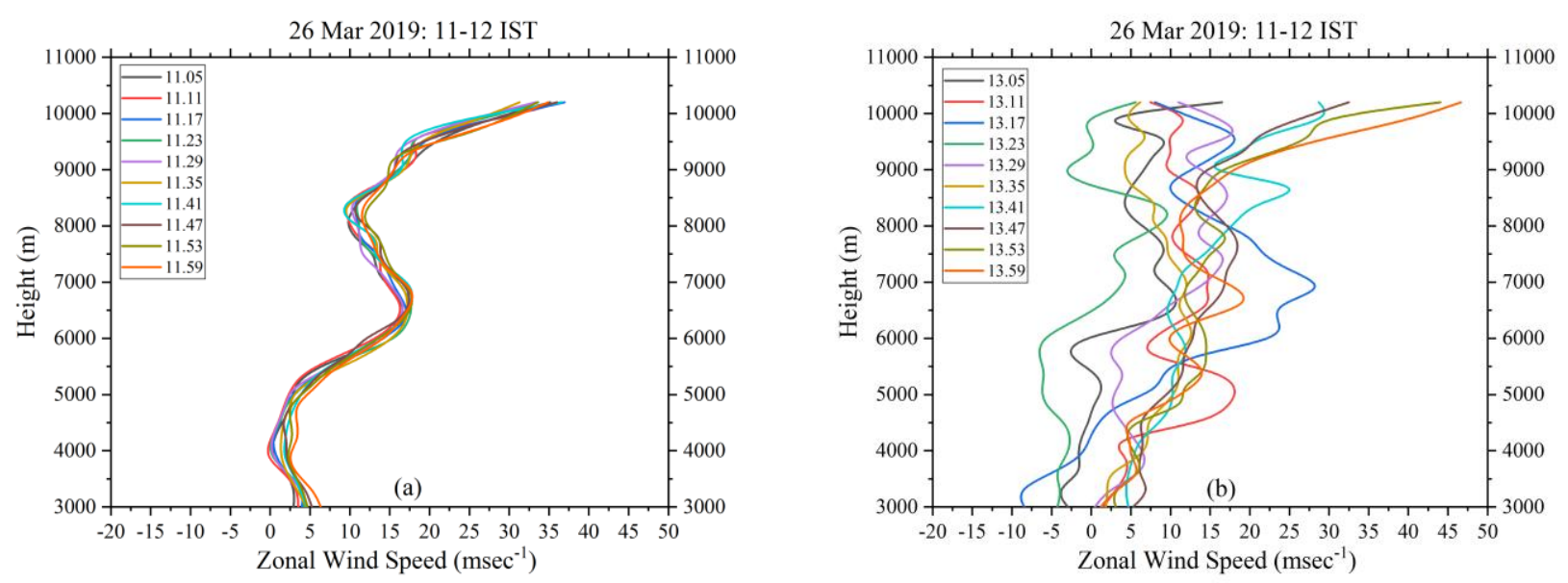

Figure 19: Modulation of zonal wind profiling(a) wind features prior to the event and (b) during athunderstorm event of March 26, 2019.

\section{Discussions}

The first results of ST Radar of Gauhati University have resulted to, in providing high quality and reliable wind parameters. The data validations are well supported both by Radiosonde and satellite observations. The wind flow patterns displayed through the analyses reflect the role of aerography in dictating the wind circulation to the zone. Interestingly, the aerography controlled flow directions derived from Radar corroborate with satellite obtained average wind circulation flow presented in Figure 1, but with far more spatio-temporal resolutions. Two of the significant wind components i.e., SE and SW are sourced at Bay Of Bengal (BoB arrowhead 4 of Figure 1). A part of SW windcomponent is trackedalong the Sub Himalayan terrain, entering through south west corridor to this zone (arrowhead 1 of Figure 1). The NE wind vector (arrowheads 2 and 5, Figure 1) more significant during Autumnal equinoxial season is induced from the north., when wind circulation pattern changes in both the hemispheres. A detailed study 
on seasonal biases in wind direction is important to understand the ocean--atmosphere coupling dynamics contributing to weather modifications. This aspect will be the future extension work ofthisstudy.

The structures embedded in wind speed and directions which might have direct association specially to the growth of rain and thunderstorm, are far more complex to identify from the profiles. It is where ST Radar proves to be an ideal system. Our analysis shows that fine spatio- temporal wind vectors with resolutions of $150 \mathrm{~m}$ and 5 minutes could provide evidences on association of qualified wind features with precipitation and thunderstorm. Perhaps, these features could beadopted as "now-casting parameters" of rain and thunderstorm events and would be potentially useful data for identifying the atmospheric environment related to thunder and associated worst weather situations.

In understanding the possible dynamical status involved in such situation, it is necessary to bring in to discussion the required conditions for development of precipitation (say) which are : (i )the air to reach saturated status, (ii) presence of lifting mechanism in this background and that (iii) the air parcel to move sufficiently up and then to cooldown thermodynamically for formation of rain drops. For such conditions a convective atmospheric system requires to be developed i.e. a well-mixed layer be present along with large humidity content controlled by local aerography. The meridional wind profiles of May 23 (Figure 20), indicated development of such a well-mixed layer where wind speed is observed to be almost independent of height unlike in a non-precipitating status (Figure17b).

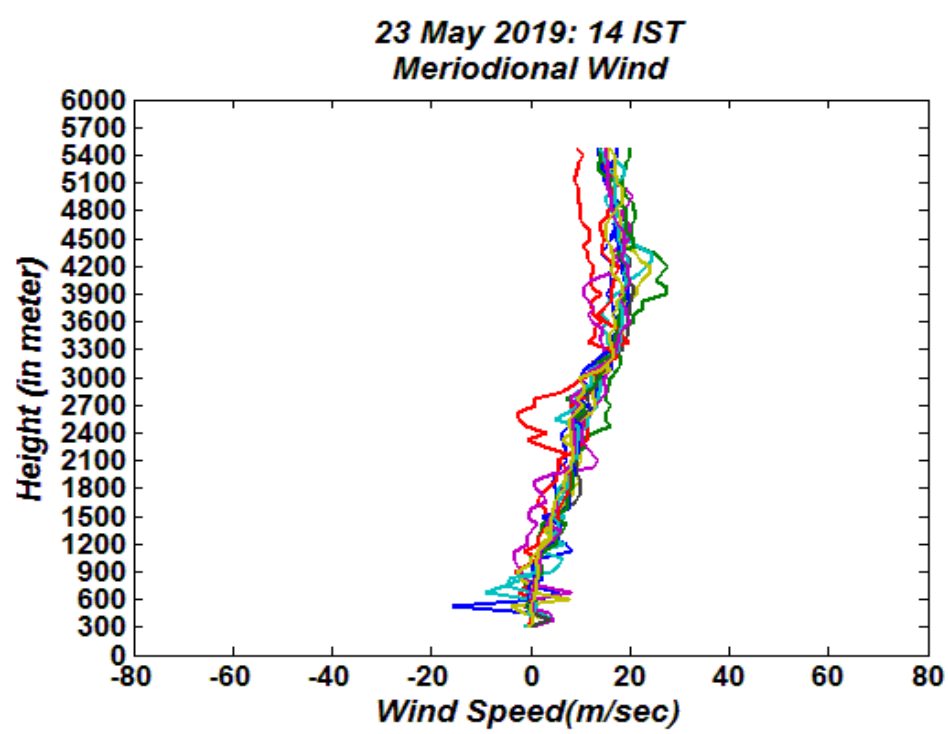

Figure 20: Meridional wind component on May $23 \mathrm{rd}$, (precipitating day). 
In the Figure 17a too, the zonal wind of May 23, shows a well maintained average speed independent of altitudes along with modulating structures, which is an index of growth of strong convective situation.

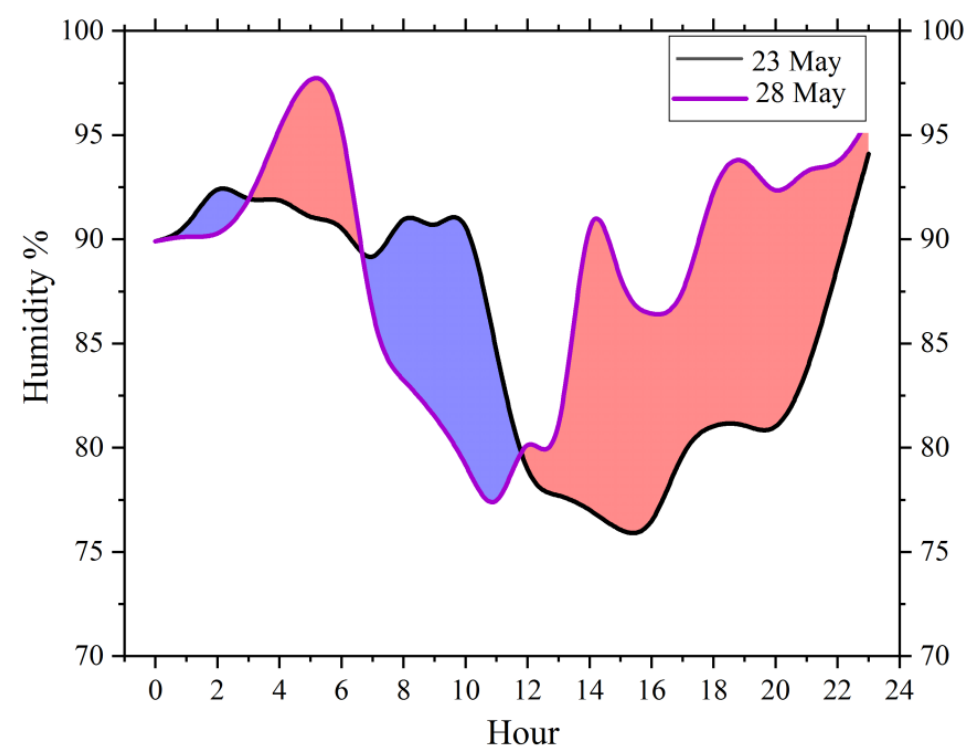

Figure 21: Presence of relatively high humidity on May 23 (rainy day) almost all along the day compared to that of May 28, 2019 (dry day). Here black \& pink lines show respectively absolute P.C of humidity present on May 28 and on May 23. The red sheds show enchantment in humidity on May 23 and the respective decrease in humidity on that day (with respect to May 28) by blue shades. Except for a short period (8 AM to 10 AM), large enhancement in humidity on May 23 is well reflected.

The situations in Figure 17 a, and Figure 20 thus show that a convective status on May 23 was strong generating a conducive environment for growth of precipitation. Along with the growth of this slab of convective layer, the humidity content on this day was sufficiently high to lead the air to saturation, compared to the relatively dry non precipitating day of May 28 (Figure 21). Presence of relatively high humidity on May 23 almost all along the day compared to that of May 28 is apparent. In the figure the black \& pink lines show P.C of humidity present respectively on May 28 and on May 23. The red sheds show enchantment in humidity on May23 (compared to May 28) and the respective decreases in humidity on that day by blue shades. Except for a short period (from 8 AM to $10 \mathrm{AM}$ ), large enhancement in humidity on May 23 is well reflected. However, these conditions alone may not be sufficient to understand dynamical status leading to growth of precipitation and it is necessary to take up more 
exclusive analysis as we plan to carry out in our next programme by adopting other relevant parameters like potential temperature and atmospheric stability indices.

The thunderstorm time modulations in wind fields (Figure 19b) show not only changes in speed in each frame of 5 minute duration but also displays development of updraft (Figure 22 marked in the figure) followed by downdraft necessary conditions for lifting the humid air to saturation and then to bring the water mass down with tremendous energy resulting to thunderstorm. The details on growth processes of thunderstorm in association with wind features are available in the paper Devietal, ( 2020).

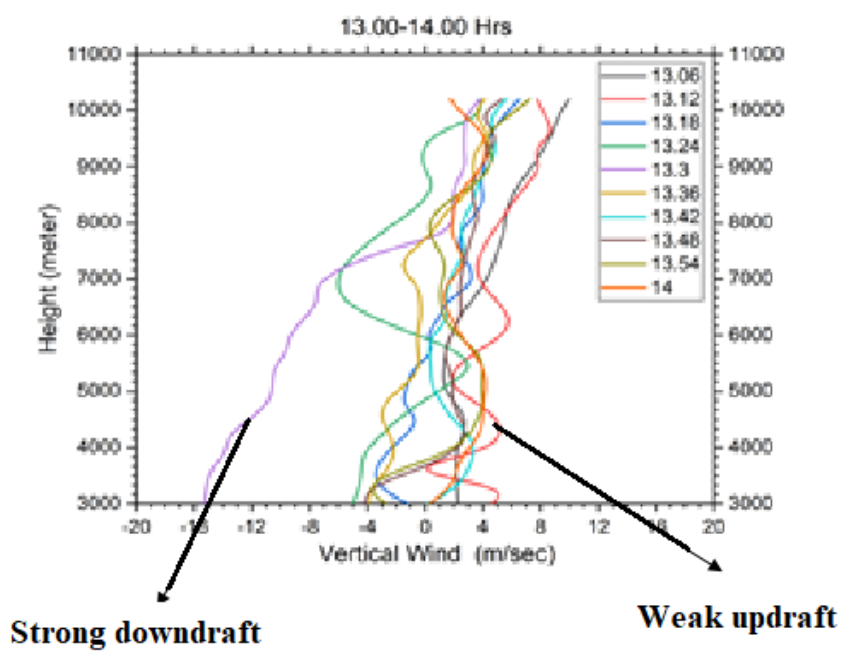

Figure22: Vertical wind speed during thunderstorm event of event of March 26, 2019. Note the draft status

Acknowledgement: The authors acknowledge with thanks Government of Assam and MeitY, Government of India and for providing financial support in creating the infrastructure facility of ST Radar. The SAMEER, Mumbai is duly acknowledged for supports in radar system development. The authors also acknowledge with thanks the RMC, Guwahati for providing Radiosonde data. The author M. Devi acknowledge with thanks the financial support received from DST funded India Indo-Russian Project entitled: project on -"Lower atmospheric forcing leading to modifications in the upper atmosphere No: DST/INT/RUS/RFBR/P-302. 


\section{Reference}

Johansson,B., and Chen,D. The influence of wind and topography on precipitation distribution in sweden: statistical analysis and modelling. International Journal of Cimatology, Vol. 23, 1523-1535. https://doi.org/10.1002/joc.951, 2003.

Devi, M., Saikia, M., Zahan ,Y., Barbara,A.K., Chen,W. Role of Aerosol laden precipitation from West Asia and hot-humid air from Bay Of Bengal in development of thunderstorm situation in NE part of India: A brief report, International Journal of Electronics and Applied Research (IJEAR), Vol. 3,No.1, https://doi.org/10.33665/IJEAR2016..v03i02.001, 2016.

Devi, M., Patgiri,S. , Medhi, A., Das, S., Saikia, M., Barbara , A.K., Kakatkar,S.S., Ray, K.P. Thunderstorm dynamics through Wind Profiling features: the first observation by Stratospheric Tropospheric Radar of GU. Natural Hazard,Springer, https://doi.org/10.1007/s11069-020-03886-0, 2020. 